\title{
CITYWIDE EFFECTS OF HIGH-OCCUPANCY VEHICLE RESTRICTIONS: EVIDENCE FROM THE ELIMINATION OF ‘3-IN-1' IN JAKARTA
}

\author{
Rema Hanna \\ Gabriel Kreindler \\ Benjamin A. Olken \\ Working Paper 23295 \\ http://www.nber.org/papers/w23295 \\ NATIONAL BUREAU OF ECONOMIC RESEARCH \\ 1050 Massachusetts Avenue \\ Cambridge, MA 02138 \\ March 2017
}

We thank Abhijit Banerjee and Daron Acemoglu for helpful comments, and Michael Fryar, Zoë Hitzig, Widyana Perdhani and Freida Siregar for helpful assistance. This project was financially supported by the Australian Government's Department of Foreign Affairs and Trade. All views expressed in the paper are those of the authors alone, and do not necessarily reflect the views any of the institutions or individuals acknowledged here, or the views of the National Bureau of Economic Research.

At least one co-author has disclosed a financial relationship of potential relevance for this research. Further information is available online at http://www.nber.org/papers/w23295.ack

NBER working papers are circulated for discussion and comment purposes. They have not been peer-reviewed or been subject to the review by the NBER Board of Directors that accompanies official NBER publications.

(C) 2017 by Rema Hanna, Gabriel Kreindler, and Benjamin A. Olken. All rights reserved. Short sections of text, not to exceed two paragraphs, may be quoted without explicit permission provided that full credit, including $(\odot$ notice, is given to the source. 
Citywide Effects of High-Occupancy Vehicle Restrictions: Evidence from the Elimination

of ' 3 -in-1' in Jakarta

Rema Hanna, Gabriel Kreindler, and Benjamin A. Olken

NBER Working Paper No. 23295

March 2017

JEL No. O18,R41

\begin{abstract}
In cities worldwide, the widespread use of single occupancy cars often leads to traffic congestion and its associated ill effects. Using high frequency data from Google Maps, we test whether highoccupancy vehicle (HOV) policies can be an effective tool to combat congestion. Using the unexpected lifting of Jakarta's HOV policy, we show that after the policy was abandoned delays rose about 39 percent on affected roads during the morning peak-and nearly $69 \%$ during the evening peak. Importantly, this was not due to simply a substitution from other roads to the former HOV routes: the lifting of the policy led to worse traffic throughout the city, even on roads that had never been restricted or at times of the day when restrictions had never been in place. The increase in traffic persisted long after the policy was lifted. In short, we find that HOV policies can greatly improve traffic conditions.
\end{abstract}

Rema Hanna

Kennedy School of Government

Harvard University

79 JFK Street

Cambridge, MA 02138

and NBER

Rema_Hanna@hks.harvard.edu
Benjamin A. Olken

Department of Economics, E52-542

MIT

77 Massachusetts Avenue

Cambridge, MA 02139

and NBER

bolken@mit.edu

Gabriel Kreindler

Department of Economics

MIT

77 Massachusetts Avenue

Cambridge, MA 02139

gabriel.kreindler@gmail.com

An online appendix is available at http://www.nber.org/data-appendix/w23295 


\section{INTRODUCTION}

Traffic congestion is a scourge of cities everywhere. In congested U.S. metropolitan areas like New York, Washington, and Atlanta, people spend, on average, over an hour a day commuting to and from work (Census, 2009). In many developing countries the figures are similar or even worse, with individuals spending on average 50 minutes daily in Mumbai, and over 1.5 hours per day commuting in São Paolo and Rio de Janeiro (Baker et al 2005, Pereira and Schwanen 2013). In addition to wasted time, traffic congestion can greatly affect urban economic activity, affecting important decisions from where to live to which jobs one would be willing to take. Moreover, it can lead to environmental damage from wasted fuel, as well as being a substantial cause of air pollution.

A commonly cited reason for congestion is the inefficiency of single-occupancy vehicles, which use a substantial amount of road capacity for each passenger transported. In response, one policy prescription is to restrict certain lanes or roads to vehicles carrying multiple passengers. First begun in the 1970s, so-called "high-occupancy vehicle" (HOV) lanes were introduced in Washington, New York, and California, and they have spread throughout metropolitan areas both in the US and, somewhat, internationally (Fuhs and Obenberger 2002).

Yet, the benefits of HOV restrictions are very unclear, with the HOV restrictions remaining quite controversial. The main concern is that HOV lanes are underused (Dahlgren 1998, Kwon and Varaiya 2008). By restricting certain lanes or roads to HOV traffic, these policies reduce the amount of available road space available for regular, single-occupancy traffic. If not enough people are induced to carpool by the existence of the HOV lane, these policies have the potential to make traffic worse on the remaining roads, since they reduce the capacity available on these roads. They may also have spillovers, either positive or negative, on other 
routes, depending on how drivers change their routes in response to the change in congestion on the HOV lanes. Equilibrium traffic responses are notoriously difficult to predict theoretically as they depend on the full traffic network and the full network of drivers' origins, destinations, times of departure, and preferences. Indeed, the well-known Braess' Paradox states that adding more roads can actually increase equilibrium congestion (Steinberg and Zangwill 1983), so what happens in practice is ultimately an empirical question. ${ }^{2}$

We examine this question by analyzing the elimination of perhaps the most extreme HOV restrictions anywhere in the world: the "3-in-1" policy in Jakarta, Indonesia. Under the 3in-1 policy, first introduced in 1992, all private vehicles during the morning and evening rush hours on the main streets of Jakarta's Central Business District were restricted to those carrying at least 3 passengers. This included all private vehicles on the 12-lane Jalan Sudirman, the city's main artery and home of the stock exchange, the education ministry, large shopping malls, and numerous corporate headquarters, as well as several other main thoroughfares. In a developing country adaptation of standard $2+\mathrm{HOV}$ restrictions, the policy required at least three passengers, rather than two, since many private car owners would also employ a driver anyway.

Jakarta is an ideal setting to study the impact of traffic congestion policies. With a population of over 30 million, Jakarta is the second-largest metropolitan area in the world, second only to Tokyo (Indonesian Census 2010, BPS 2015a, BPS 2015b). Virtually all commuters in the region use the roads in some form or another: the city has no subway or light rail system, and only a very limited commuter rail network. ${ }^{3}$ Not surprisingly, then, it has some

\footnotetext{
${ }^{2}$ In fact, many other traffic policies aimed at reducing congestion and pollution, such as even-odd license plate policies, have been found to be ineffective in practice due to unexpected human behaviors (see, for example, Davis, 2008; Gallego, Montero, and Salas, 2013).

${ }^{3}$ The commuter rail network carries 224 million passengers per year in the Jabodetabek region, compared to 961 million per year by the Delhi metro, 1.7 billion on the New York subway (BPS Jakarta 2014, DMRC 2015, MTA facts http://web.mta.info/nyct/facts/ridership/ridership_sub_annual.htm)
} 
of the world's worst traffic: a recent study of cities around the world using GPS data found that the typical Jakarta driver experienced an average of 33,240 "stops and starts" in traffic per year, the worst in the world. By this metric, traffic jams in Jakarta are more than twice as severe as the worst-ranking U.S. city, New York, where drivers average only 16,320 stops and starts. ${ }^{4}$

In this paper, we study the elimination of the 3-in-1 policy on traffic speeds throughout the city using innovative, high-resolution data collected via Google Maps. On Tuesday March 29, 2016, the Jakarta government unexpectedly announced the abolition of the 3-in-1 restrictions, effective 7 days later. To study the impact of this change, starting two days after the announcement (Thursday afternoon, March 31), we began collecting real-time data on driving speeds on several main roads in Jakarta - including some roads affected by the 3-in-1 policies, and several alternate unaffected routes - by querying the Google Maps API for each route, every 20 minutes, 24 hours per day. We expanded our data collection to include additional alternate routes suggested to us by the Government of Jakarta, as well as even finer time frequency, several weeks later.

To study the effects, we rely on two alternative counterfactuals. First, we use pre-period data from the 2-3 days before the policy took effect. Second, we take advantage of Google's own innovative prediction algorithms by asking Google to predict the expected trip duration, for each route, day of the week and departure time, under typical traffic conditions. These predictions essentially use all of the data on average road speeds Google has been collecting. We show both counterfactuals are virtually identical: the speeds we observe during our pre-period correspond almost exactly to the typical "predicted" speeds from Google Maps, suggesting that the use of Google Map predictions on the routes for which we did not observe pre-period data are likely

\footnotetext{
${ }^{4}$ See the Castrol Stop-Start Index: http://www.castrol.com/en_au/australia/car-engine-oil/engine-oil-brands/castrolmagnatec-brand/stop-start-index.html
} 
quite accurate.

We begin by documenting the impact of the elimination of the HOV restrictions on the affected roads. Not surprisingly, elimination of the HOV restrictions led to an increase in delays in areas and during the time intervals where the restrictions had been in place. Delays - which we measure as the typical number of minutes required to travel each kilometer (i.e. the inverse of speed) - rose by between 39-45 percent during the morning peak period and by between 69 to 85 percent during the evening peak period, depending on which counterfactual we use. This translates into a decline in average morning rush hour speeds from $28 \mathrm{~km} / \mathrm{h}$ to $20 \mathrm{~km} / \mathrm{h}$ in the morning and a decline in evening rush hour speeds from $21 \mathrm{~km} / \mathrm{h}$ to $12 \mathrm{~km} / \mathrm{h}$. This is extremely congested: by comparison, typical walking speeds are about $5 \mathrm{~km} / \mathrm{h}$.

Even more surprising, the elimination of the HOV restrictions during the morning and evening rush - from 7-10am and 4:30-7pm - also led to increases in congestion at other times of the day. In particular, on the main HOV road in the hour after the evening peak (i.e. from 78pm), which was never restricted even during the HOV policy period, we find increases in delays of 50-53 percent. For the middle of the day, which was again never restricted, depending on the specification, we either find no change in average delay, or an increase of 17 to 30 percent.

We then turn to examine whether there were any positive or negative spillover effects of the HOV restrictions on other roads. We examine two roads in particular, each of which parallels part of Jalan Sudirman and were thus considered primary alternate routes during the HOV period. One would expect that, after the elimination of the HOV restrictions, congestion should decrease on these alternate routes, as traffic induced to use these routes would substitute back to Sudirman once it became open. Yet we find the opposite: delays on the two main 
alternate routes also increase - by around 13 percent during the evening commute. The delay during the middle of the day also goes up by about 23-27 percent on one of the alternate roads, and does not change on the other. In short, the direction of these spillovers suggest that the removal of the HOV policy had a negative general equilibrium effect on traffic.

These negative effects appear to persist over time, and are robust when we expand to an even larger sample of both former HOV roads and never HOV roads. We continue our main analysis through June 3, which is the start of the holiday of Ramadan. ${ }^{5}$ The results look similar: substantially more traffic not just on the roads where restrictions were eliminated, but substantially more traffic on other alternate routes when restrictions were never in place, and at other times of day when restrictions were not in place.

There are, broadly speaking, two potential reasons why eliminating HOV restrictions could lead to a general equilibrium increase in congestion. The most parsimonious explanation is that substantially more people are induced to drive once the HOV restrictions are eliminated: once these people have their cars at work, they drive them at other times of day, creating more traffic. The other potential reason is through the feeder aspect of the road network: it is possible that some people are trying to get to the now-congested $\mathrm{CBD}$, and the congestion in the $\mathrm{CBD}$ spills back to other parts of the network. Although our data do not allow us to disentangle these hypotheses directly, the data seem most consistent with an increase in the overall quantity of cars being responsible: we find an increase in traffic even on one alternate route that heads away from the CBD, where such upstream congestion effects would be unlikely.

The magnitude of the effects is remarkable, and significantly larger than typical effects in

\footnotetext{
${ }^{5}$ We end our main analysis with the start of Ramadan, since traffic patterns change during the month of Ramadan; in particular, the last 1-2 weeks of Ramadan are effectively a national holiday, and since virtually all businesses shut down there is never any traffic during this period. These patterns are visible in Figures 4A and 4B, which includes data until August 18.
} 
the literature. For example, in the 7-8 pm time period - when 3-in-1 was never in effect - we find that eliminating 3-in-1 led to increases of delays of 1-1.9 minutes per kilometer, even on alternate roads. By contrast, estimates are that London Congestion Charge led to a decrease in delay of 0.6 minutes per kilometer (TfL 2006). Anderson (2014) finds that a public transport strike in Los Angeles leads to an increase of between 0.2 and 0.4 minutes of delay per mile during peak hours on highways throughout the city. Kreindler (2016) studies the introduction of short-term driving restrictions based on license plate numbers in Delhi, and using similar Google Maps data finds an improvement of around 0.2 minutes per kilometer across the city.

These relatively large effects are even more notable given the challenges of implementing HOV policies in a developing country context. In particular, in Jakarta, there was a widespread practice of hiring people, known as "jockeys," to serve as extra passengers in order to enter the 3-in-1 restricted areas (hiring a jockey cost around Rp. 15,000 (US\$1.20) each way). Had the widespread use of jockeys compromised the policy, we would expect little or no effect of the lifting. The evidence emphatically rejects this view, as the lifting of 3 -in-1 made a large difference to traffic congestion. Instead, the presence of jockeys still created a substantial additional marginal cost for entering the 3-in-1 area, which reduced congestion. The large impact of lifting 3-in-1 we observe, combined with the presence of jockeys during the 3 -in-1 period, is indicative of a large demand elasticity of single-occupancy vehicles, a large marginal rate of congestion, or both.

The remainder of paper is organized as follows. Section 2 describes the policy in more detail and describes the data. Section 3 presents results, and Section 4 concludes. 


\section{SETTING AND DATA}

\section{A. Setting}

Rising incomes in many developing and emerging nations has led to a dramatic increase in car ownership: in Jakarta, Indonesia - the setting of this study - the number of registered passenger cars doubled between 2004 and 2014, from 1.64 to 3.26 million vehicles (Statistik Transportasi Jakarta 2009, 2015). ${ }^{6}$ Much of the travel throughout the city is on the roads, as the city has no subway or light rail system, and only a very limited commuter rail network. In fact, "more than 10 million motor vehicles roam Jakarta each workday, even though roads and highways constitute less than 10 percent of its total land area". As incomes rise, cars are also more likely to carry fewer passengers. In Jakarta, from 1985 to 2000 the average private car occupancy rate went from 1.96 to 1.75 (Susilo et al 2007).

In response to heavy traffic, the Jakarta government instituted the "3-in-1" policy in March 1992. The policy requires cars to have at least 3 passengers (including the driver) in both directions on the major corridors Jalan Sudirman - Jalan Thamrin and Jalan Gatot Subroto (See Figure 1). Initially, the policy only applied in the morning, between 6AM and 10AM between Monday and Friday. In December 2003, enforcement of the policy was improved, and the evening peak was included; the operating hours changed to 7-10AM and 4:00-7PM (JICA 2004). The evening hours were changed to 4:30-7PM in September 2004, and from 2004 to 2016 there were no changes in the system. Disobeying the 3-in-1 rule fell under disobeying road signs, the fine for which is a maximum of IDR 500,000 (approximately USD 37.5) or 2 months in prison. ${ }^{8}$

\footnotetext{
${ }^{6}$ Over the same period, the number of motorcycles more than tripled, from 3.94 to 13.08 million vehicles.

${ }^{7}$ Quote from the April 102016 New York Times article "Gridlocked Jakarta Becomes Even Worse, at Least for a Week" by Joe Cochrane: http://www.nytimes.com/2016/04/11/world/asia/gridlocked-jakarta-becomes-even-worseat-least-for-a-week.html.

${ }^{8}$ See the 3-in-1 regulation by the Governor of Jakarta DKI (No 4104/2003), and the Road Traffic and Transport national Law 22/2009.
} 
The policy was not necessarily popular, with many believing that it did little or nothing to help reduce Jakarta's notorious traffic (Mochtar and Hino 2006). ${ }^{9}$ Moreover, the policy has led to the development of professional passengers, called "jockeys." Jockeys stand by the road near 3in-1 access points, and provide an additional passenger in exchange for a payment to the jockey of about the equivalent of US\$1.20. In fact, a single driver in need of two additional passengers can hire a mother and child standing on the side of the road to provide another two bodies in the car. $^{10}$

In late March 2016, the Jakarta government announced that the 3-in-1 policy would be temporarily lifted. This surprise announcement was motivated by an unrelated development, where the Jakarta police uncovered a ring of beggars that drugged children. ${ }^{11}$ The focus soon moved to mother jockeys and their infant children standing by the roadside, prompting Jakarta Governor Basuki Purnama (also known as Ahok) to denounce the 3-in-1 policy on March 29, 2016 and announce that it would be lifted effective 7 days later, for a one-week trial period. ${ }^{12}$ The initial one week trial was first extended for another month and then the policy was permanently scrapped on May $10,2016 .^{13}$

\footnotetext{
${ }^{9}$ See also: Muhammad Syarifullah (2015), Governor Ahok's Policy to Solve Jakarta's Traffic Jams, New Cities Summit, Perspectives. http://www.newcitiesfoundation.org/governor-ahoks-policy-to-solve-jakartas-traffic-jams/

10 Jakarta Jockeys Feel the Squeeze as 3-in-1 Scheme Runs Out of Gas, Jakarta Globe, October 21, 2012, http://jakartaglobe.id/archive/jakarta-jockeys-feel-the-squeeze-as-3-in-1-scheme-runs-out-of-gas/

${ }^{11}$ The arrests in this case were made on March 24 and 25 (Gov't vows to end child begging after 4 arrested for beating and drugging exploited children in South Jakarta, Coconuts Jakarta, March 28 2016, http://jakarta.coconuts.co/2016/03/28/govt-vows-end-child-begging-after-4-arrested-beating-and-druggingexploited-children)

${ }^{12}$ See Pekan Depan, Ahok Ujicoba Hapus Peraturan 3 in 1 (Next week, Ahok Tests Removing the 3 in 1 Rule) Poskota News, Tuesday, March 29, 2016, http://poskotanews.com/2016/03/29/pekan-depan-ahok-ujicoba-hapusperaturan-3-in-1/

13 For the extension see: 3-in-1 Removal Trial Extended to Four Weeks, Tempo, April 14 2016, http://en.tempo.co/read/news/2016/04/14/057762681/3-in-1-Removal-Trial-Extended-to-Four-Weeks.

Regarding the permanent removal of 3-in-1 see: Dishub DKI Jakarta: Aturan 3 in 1 Dihapus, Liputan 6, May 10 2016, http://news.liputan6.com/read/2503360/dishub-dki-jakarta-aturan-3-in-1-dihapus
} 


\section{B. Data}

Our primary data on traffic congestion levels comes from Google Maps, specifically from repeated queries we made to the Google Maps Distance Matrix API. Google Maps uses real-time data collected from hundreds of millions of Android phones to estimate speed conditions on roads around the world.

We obtain two types of data from the Google Maps system for our selected routes. First, we query "live" traffic data for each route every 20 minutes in order to construct a measure of road speeds. This data captures current travel conditions based on real-time reporting of traffic conditions from Android smartphone users, and is intended for real-time navigation. ${ }^{14}$ We report these metrics in terms of "travel delay," defined as the number of minutes that are necessary to advance 1 kilometer, on average over the course of a route.

In addition to the "live" data, we also collected data on "predicted" business-as-usual traffic. This captures typical travel time on a given day of the week and at a particular time of the day, based on historical data captured by Google. Specifically, for this type of query, we set the departure time on a particular time of day and day of the week, but on a distant date several weeks in the future. Since the date is far in the future, this estimate incorporates all historical averages, but no real-time data. We show below that these predicted business-as-usual traffic numbers are indeed accurate forecasts of traffic conditions prior to the 3 -in-1 lifting, and also appear to be very stable over time. In particular, this means that "predicted" queries made after the policy was lifted continue to accurately represent the pre-policy lifting counterfactual.

We collected data in two phases. Starting on March 31 at $2 \mathrm{pm}$ WIB, approximately 48 hours after the announcement but 2.5 "weekday" days before the 3-in-1 policy was lifted, we

\footnotetext{
${ }^{14}$ We obtain this type of data from the Google Maps API by setting the desired trip departure time to "now" at the time when the query is made.
} 
began collecting the traffic data in both directions on three main roads (see Figure 1): Jalan Sudirman, Jakarta's main artery and a road subject to the HOV policy, and two alternate roads that run parallel to parts of Jalan Sudirman that were never subject to the HOV policy: Jalan Rasuna Said (another main CBD road with many office towers), and Jalan Tentara Pelajar (a main artery leading into the CBD from the southwest). For these roads, we collected "live" data by querying the Google Maps API every 20 minutes, 24 hours per day. Thus, we have data from both before and after the policy was lifted. As discussed above, we also collected predicted data on the same routes, separately for every day of the week and for the same departure times as the real-time data queries. ${ }^{15}$

Starting on April 28, 2016, we expanded our dataset to include an additional previously HOV road, Jalan Gatot Subroto, as well as 10 alternate routes that had never been subject to HOV restrictions. These 10 alternate routes were suggested to us by the Jakarta Government Department of Transportation. ${ }^{16}$ At this time, we also increased our data collection frequency to one query every 10 minutes. As with the earlier roads, we also queried the "predicted" data for comparison. ${ }^{17}$

Appendix Table 1 provides some summary statistics for the traffic delays on both the former HOV road of Jalan Sudirman (Panel A) and its alternate roads (Panel B and C), using live data before the policy was lifted. Traffic is clearly bad, averaging 2.8 minutes per $\mathrm{km}$ on the

\footnotetext{
${ }^{15}$ The departure date was chosen between April 18 and April 20 for weekdays, and May 21-22 for weekend. The queries themselves were made both before and after the lifting of the policy, between April 3 and April 12. We show in Appendix Figure 6 that "predicted" Google Maps data changes very slowly. In other words, the algorithm used to predict typical travel times is only slowly influenced by recent developments.

${ }^{16}$ Following the recommendations of the Jakarta Government, the revised data for Jalan Sudirman and Jalan Rasuna Said collected after April 28 included very slight modifications of the start and end points of the routes, to better match the standard route definitions they use. We collected data on both the original, and revised, definitions for these two routes for an overlap period from April 28 to May 6. In Appendix Figure 4 we show that on the period of overlap, the two sets of queries agree for both the live and predicted values despite the very small differences in exact origin and departure locations.

${ }^{17}$ The departure date was chosen between May 16 and 22. The queries were made on May 2, 3 and 4.
} 
former HOV road from $7 \mathrm{am}-8 \mathrm{pm}$, and 3.3 and 2.2 minutes per $\mathrm{km}$ on the two alternate roads. Certain time intervals have significantly worse congestion, up to 3.6 and 4.4 minutes per $\mathrm{km}$. By comparison, average delay is 0.7 minutes per kilometer $(53 \mathrm{mph}$ ) on the Los Angeles highways studied in Anderson (2014). In Delhi, another congested city, delays are 2.6-2.7 minutes per km on average between 8am and 8pm over many routes across the city (Kreindler 2016).

The pre-data also contains suggestive evidence that the HOV policy was effective in reducing traffic at the restricted times of the day. Specifically, on Jalan Sudirman, the delay is lower during the morning and evening peaks, relative the mid-day off-peak and the hour after the evening peak, respectively. On the two non-restricted roads, the opposite pattern holds. While suggestive, these results could be due to underlying travel demand differences across the three roads. Moreover, we do not know if the HOV restrictions simply diverted cars to other roads or time periods, or reduced the number of cars on the road. To explore these issues more rigorously, we next study the effect of the unexpected lifting of the 3-in-1 policy.

\section{RESULTS}

A. Effect of Lifting "3-in-1" on Jakarta's main arterial CBD roads (Jalan Sudirman) and its alternate roads

We begin our analysis by comparing traffic both right before and after the policy. In Figure 2, we graph the average delay in minutes per kilometer on the weekdays for the former HOV road Jalan Sudirman (Panel A), as well as two alternate roads (Jalan Rasuna Said in Panel B and Jalan Tentara Pelajar in Panel C). We average over both road directions (North and South) since there are strong traffic flows in both directions at both times. ${ }^{18}$ The dashed-line denotes the pre-period

\footnotetext{
${ }^{18}$ In Appendix Figures 1A and 1B, we disaggregate the data by North- and South-bound respectively. The results are very similar to the averaged figures. Traffic is worse after the policy is lifted in both the morning and evening
} 
days of March $31^{\text {st }}$ (from 2pm onwards), April 1 and April 4, while the solid-line denotes the post-period from April $5^{\text {th }}$ to May $4^{\text {th }} .{ }^{19}$ Note that, here, we only examine what occurred during the first month after the policy change in order for our post-period to be as comparable as possible to the pre-period, as we worry that factors - e.g. city-wide changes in school schedules, income, weather, etc.- may eventually change over time (we will lift this restriction in Section III.B. to explore what happens over time). Bootstrapped 95 percent confidence intervals, clustered by date and direction are shown shaded. For convenience, we also denote the rush hour times during which the 3-in-1 policy was in effect during the pre-period.

Traffic clearly increased after the HOV policy was lifted. On the former HOV road (Panel A), we observe traffic increasing in both the morning and evening peak. This could be due to one of two factors: (1) after the abolition of the 3-in-1 policy, the number of trips increased and there are more cars on the road (e.g., people stopped carpooling, stopped using bus transit, or increased their likelihood of travel to and from the CBD) or (2) the number of cars on the road is the same, but people changed the times of day when they travel, or their route. Figure 2 also shows that (2) is unlikely. If anything, we observe an increase in traffic on the former HOV road during non-peak hours (Panel A) - especially after 7pm, when HOV restrictions were never in place. Moreover, we do not observe any changes in traffic on the alternate routes in the

rush hours on the former HOV road (Panel A), albeit the effect is most pronounced in the evening peak heading Southbound, which is consistent with slightly more residential areas being located south of the CBD than north of the CBD. Traffic is also higher in the non-rush hour periods on the former HOV road. For the alternative road of Jalan Rasuna Said (Panel B), traffic is worse in the midday period in the Northbound direction and in the midday, evening peak and evening in the Southbound direction, and otherwise the same. For the alternative road of Jalan Tentara Pelajar (Panel C), traffic is slightly worse in the evening rush hour, but clears up in the morning rush hour northbound, after the policy is lifted.

${ }^{19}$ As soon as the policy experiment was announced, we began to collect data. However, this means we only have 2 full days of traffic data before the policy was lifted (the Friday and Monday before). This is a problem if traffic is significantly different on different days of the week, since we are comparing the pre-days of Monday and Friday with all potential weekday days after the policy change. Thus, as an additional robustness check, we can constrain our entire analysis to just Monday and Fridays both pre and post the policy. As shown in Appendix Figure 2, the results are near identical. The sign and magnitude of impacts by road and time interval is very similar to Figure 2, with the exception of the mid-day off-peak on Jalana Surdirman, where we find no effect. This analysis implies that overall our findings are not driven by just having two days of pre-data. 
morning peak hours and actually observe an increase in traffic on the alternate routes in the evening rush hour. This implies that individuals are not just changing their travel time or routes, but rather there must be more cars on the road, leading to more traffic overall throughout the city.

Table 1 formalizes Figure 2. Specifically, we estimate, separately for each road segment and time period, the following equation:

$$
\text { delay }_{i d h}=\alpha+\beta \cdot \text { post }_{d}+\gamma \cdot \text { north }_{i}+\varepsilon_{i d h}
$$

where delay $y_{i d h}$ is the average travel delay in minutes per kilometer for segment $i$, on date $d$ and for departure time $h$, nort $_{i}$ is an indicator for whether segment $i$ is northbound, and post $_{d}$ is an indicator for dates after the lifting. ${ }^{20} \beta$ is the coefficient of interest, providing the difference in average delays after the policy is lifted. Each column in Table 2 restricts the sample of departure times $h$. We provide $\beta$ for both the morning (Column 2) and evening rush hours (Column 4) where 3-in-1 restrictions were in place in the pre-period, as well the non-peak periods (Columns 1, 3, 5 and 6) which were always unrestricted on all roads. Standard errors are clustered by date and direction.

The results in Table 1 echo the graphical findings from Figure 2. Table 1, Panel A shows that traffic is worse on the former HOV road once the policy is lifted. Specifically, we observe a 0.96 minutes $/ \mathrm{km}$ increase (45 percent increase over control mean of 2.14 minutes $/ \mathrm{km}$ ) in travel delay during the morning rush hour (significant at the 1 percent level, Column 2) after the policy

\footnotetext{
${ }^{20}$ We perform several robustness checks. Appendix Table 2 provides the same regression analysis, but using the average delay over both directions for each road. The results are virtually identical to Table 1. In Appendix Table 3, we constrain the analysis to Thursday afternoons, Mondays and Fridays (since we only have pre-data for these days). Again, the results are qualitatively similar - traffic is worse on the former HOV road during peak hours and is generally the same or worse at alternative times on the HOV road or on alternative roads-although we lose statistical precision in some cases due to the much smaller sample sizes. We also do not observe any impact during the mid-day off-peak on Jalan Sudirman. Finally, Appendix Table 4 replicates Table 1 using a regression discontinuity specification, restricting the sample to one week after the policy lifting, and including a linear control for the number of days relative to the lifting. Again, the results are very similar to Table 1.
} 
is lifted and a 2.4 minutes $/ \mathrm{km}$ ( 85 percent) increase in the evening rush hour (significant at the 1 percent level, Column 4).

The impacts on excess travel delay are remarkably large. Excess travel delay is defined as the travel delay above and beyond the delay under free-flow condition. The logic of this measure is that the delay corresponding to free-flow is not affected by policies such as 3 -in- 1 . We approximate free-flow conditions using night-time delay, which is around 1.7-1.9 minutes per kilometer for all three roads. Using this metric, on Jalan Sudirman excess travel delay goes up 3.5 and 2.5 times during the morning and evening peak hours, respectively.

The increase in delay occurs at other times when no HOV restrictions were in place even in the pre-period. Specifically, traffic delays also increase during the hour immediately after the evening rush hour by 1.9 minutes $/ \mathrm{km}$ (53 percent) (Column 5). We observe any change in traffic neither in the hour before the morning rush hour (Column 1) nor at night (Column 6). Traffic delay increases by 0.54 minutes $/ \mathrm{km}$ during the midday period. ${ }^{21}$ This implies that individuals are not simply substituting away from travelling at other time periods once the 3 -in-1 policy is lifted.

Similarly, we do not observe a substitution away from alternate roads once the policy is lifted (Panel B and $\mathrm{C}$ of Table 1). In fact, traffic actually increases on alternate routes, particularly in the evening rush hour where we observe a 0.57 minutes $/ \mathrm{km}$ (13 percent) increase in delay on Jalan Rasuna Said and a 13 percent increase in delay on Jalan Tentara Pelajar. In short, these spillovers to other time periods and the alternative roads imply an overall negative effect on traffic congestion when the HOV policy is lifted.

\footnotetext{
${ }^{21}$ Note that in Appendix Table 3, which includes day of week fixed effects and restricts to the same weekdays (Monday and Friday) in both pre- and post- periods, there is no change in delay in the midday period.
} 


\section{B. Extending the Analysis across Time and Location}

The analysis in Section III.A. suggests that traffic increased from the immediate period before and after the policy change on Jakarta's main arterial road and its associated alternate roads. We can now extend the analysis in two ways: (1) we can explore what happened to traffic over time, as individuals learned that traffic conditions worsened over time, and (2) what was happening in the rest of the road network.

\section{Constructing and validating counterfactuals for additional routes}

As Jakarta's 3-in-1 policy experiment was announced shortly before it occurred, we have limited data prior to the policy lifting -2.5 days of pre-period data for the former HOV road of Jalan Sudirman and two alternate roads, at 20 minute intervals. Starting on April 28, we began to collect data on Jalan Sudirman at 10 minute intervals with a slight change in precise route definition, ${ }^{22}$ as well as data for another HOV road (Jalan Gatot Subroto) and 10 total alternate routes to Jalan Sudirman and Jalan Gatot Subroto suggested by the Jakarta government. For these routes and dates, we do not have comparable pre-policy lifting "live" data.

Instead, to extend the analysis to these additional routes, we can rely on Google Maps' predicted travel time data as a counterfactual of what would have happened in the absence of the policy lifting. Due to time-lags and smoothing in their prediction algorithm, this predicted data does not take into account the change in policy. ${ }^{23}$ In order to rely on this data, we must first be convinced that the "predicted" data provides an accurate counterfactual. Therefore, we conduct a number of checks to determine whether this is the case.

\footnotetext{
${ }^{22}$ We show in Appendix Figure 4 Panel A that this change in definition produces very similar results. Specifically, during the overlap period April 28-May 6 when both queries were running at the same time, the travel delay we obtain is very similar regardless of the definition.

${ }^{23}$ We show this in Appendix Figure 6, where we compare the predictions for our three main roads from data obtained 2 days before the policy lifting, one week after the policy lifting, and one month after the policy lifting (which is when we obtained the predictions on the alternative routes). These three predictions are virtually identical, except for a very slight increase in traffic on Sudirman (Panel A) in the evening rush period. In any case, any adjustment would tend to bias our results towards the null of finding no effect.
} 
First, in Appendix Figure 3, we compare our "live" pre-period data for the former HOV road of Jalan Sudirman and its alternate roads with the predicted data. For Jalan Sudirman (Panel A), the live and predicted data track each other perfectly in the pre-period. For the alternate roads, the live and predicted data track each other perfectly, except for a total of two time period-road pairs: the evening rush hour on Jalan Rasuna Said (Panel B) and the morning rush hour on Jalan Tentara Pelajar (Panel C), where in both cases the live data is slightly above the predicted.

Second, we can examine how our previous results would have looked had we used the predicted data. To do so, we can re-run Table 1, but use the predicted data rather than the live pre-data as our comparison group. Specifically, we run the regression

$$
\text { delay }_{i d h p}=\alpha+\beta \cdot \mathbf{1}(p=1)+\gamma \cdot \operatorname{north}_{i}+\varepsilon_{i d h}
$$

where delay $y_{i d h p}$ denotes delay on route $i$ on date $d$ for departure time $h$, and live or predicted for $p=0$ and $p=1$, respectively. In the sample, we include all weekdays between April 28 and June 3 for the live data $(p=0)$, as well as the five weekdays of predicted data $(p=1)$. Once again, we restrict the departure time $h$ in different columns of the table.

Appendix Table 5 provides these results, and shows that our findings would be the same - the lifting of the 3-in-1 policy led to increased traffic both on the former HOV road during rush hours, but also at other hours and on the alternate roads. Altogether, this implies that the historical traffic prediction provides a valid counterfactual of the absence of the policy.

\section{Results}

We now use the predicted data to explore the effect of the policy over a larger network of roads and over time. Figure 3 graphs the live post-data against the predicted traffic data for the 
extended set of HOV roads (Panel A) and alternate routes (Panel B) for April $28^{\text {th }}$ to June $3^{\text {rd }} \cdot{ }^{24}$

Table 2 provides the corresponding set of regressions. As before, we observe an increase in traffic for both the morning and evening rush hours for the former HOV roads after the policy is lifted - the evening rush hour delay is nearly $70 \%$ higher than the predicted delay (Column 4 of Table 2, Panel A). Again, we also observe both an increase in traffic in the non-rush hour times of the former HOV roads (Panel A of Table 2), as well as a significant increase in traffic on the alternate routes (Panel B of Table 2). In fact, the alternate routes experience a $21 \%$ increase in traffic delays in the midday period, a $28 \%$ increase in the evening rush hour and a $34 \%$ increase in the hour after rush hour.

We can also look more closely at how the effect changes over time. In Figures 4A and 4B, we plot the average traffic delays each day, as well as the predicted travel delay, from April 28 to August $16^{\text {th }}$ for the morning rush hour, the mid-day off-peak, the evening rush hour, and the hour after the evening peak. Figure 4A does so for the former HOV roads, while Figure 4B does so for the alternate routes. ${ }^{25}$ The figures show that the effect of the policy persists over time on both the HOV and alternate roads, drops during the holiday of Lebaran (when many Jakarta residents travel to their native regions), and increases again relative to the predicted after the holidays, albeit smaller in magnitude after the holiday ends.

\section{CONCLUSION}

In this paper, we show that the lifting of Jakarta's 3-in-1 policy not only had effects on traffic on

\footnotetext{
${ }^{24}$ Appendix Figure 5 shows the results separately by direction. The results are similar, with a slightly more pronounced evening peak in the southbound direction.

${ }^{25}$ Appendix Figures 7A, 7B and 7C show the equivalent figures for Jalan Surdirman and its alternate routes from April 1 to August 16. They show similar patterns: a stark increase in traffic delays the day after the policy is lifted, followed by a continued increase in traffic, a decline in traffic during the holiday of Lebaran, and an increase again in the post period (although slightly lower in magnitude than before the holiday period).
} 
former HOV roads, but had spillovers to alternative roads and time periods. In short, more cars were on the road. Quite notable is the speed of the adjustment to this new equilibrium: essentially, within a couple of days the delay pattern corresponding to the new equilibrium was achieved.

We cannot decisively say whether the 3-in-1 policy improved welfare. This depends on how commuters with cars value the alternatives to single occupancy cars (e.g. carpooling, taxi, public transport, or not travelling). However, given the extremely high congestion levels, we can infer that the wedge between private and social cost is also high, making it likely that the equilibrium after the lifting is severely inefficient.

\section{REFERENCES}

Anderson, Michael L. (2014), Subways, Strikes, and Slowdowns: The Impacts of Public Transit on Traffic Congestion, American Economic Review 2014, 104(9): 2763-2796

Baker, Judy, Rakhi Basu, Maureen Cropper, Somik Lall and Akie Takeuchi (2005), Urban Poverty and Transport: The Case of Mumbai, World Bank Policy Research Working Paper 3693, September 2005

Dahlgren, Joy (1998). High occupancy vehicle lanes: not always more effective than general purpose lanes, Transportation Research Part A: Policy and Practice. Volume 32, Issue 2, February 1998, 99-114.

Davis, L. W. (2008). The effect of driving restrictions on air quality in Mexico City. Journal of Political Economy, 116(1), 38-81.

Delhi Metro Rail Corporation (DMRC) (2015), Annual Report 2014-2015.

Fuhs, Chuck and Jon Obenberger (2002), Development of High-Occupancy Vehicle Facilities Review of National Trends. Transportation Research Record 1781, Paper No. 02-3922

Gallego, F., Montero, J. P., \& Salas, C. (2013). The effect of transport policies on car use: Evidence from Latin American cities. Journal of Public Economics, 107, 47-62.

Governor of the DKI Jakarta (2003), Decision No. 4104/2003 Penetapan Kawasan Pengendalian Lalu Lintas Dan Kewajiban Mengangkut Paling Sedikit 3 Orang Penumpang Perkendaraan Pada 
Ruas - Ruas Jalan Tertentu Dipropinsi Daerah Khusus Ibukota Jakarta.

Indonesian Central Bureau of Statistics (BPS) (2014). Statistics Commuter Jabodetabek.

Indonesian Central Bureau of Statistics (BPS) (2015a), Banten Penduduk Menurut Jenis Kelamin dan Kabupaten/Kota di Provinsi Banten, 2005-2015, http://banten.bps.go.id/linkTableDinamis/view/id/51

Indonesian Central Bureau of Statistics (BPS) (2015b), Satudata Jawa Barat Jumlah Penduduk Kabupaten/ Kota di Jawa Barat Tahun 2010 - 2015, http://pusdalisbang.jabarprov.go.id/pusdalisbang/data-94-Kependudukan.html

Jakarta Central Bureau of Statistics (Badan Pusat Statistik Provinsi DKI Jakarta) (2009), Statistik Transportasi DKI Jakarta Tahun 2009, Katalog BPS 8215.31.

Jakarta Central Bureau of Statistics (Badan Pusat Statistik Provinsi DKI Jakarta) (2015), Statistik Transportasi DKI Jakarta Tahun 2009, Katalog BPS 8301007.31.

Japan International Cooperation Agency (JICA) and Badan Perencanaan Pembangunan Nasional (BAPPENAS), The Study on Integrated Transportation Master Plan for JABODETABEK (Phase II) Final Report, Pacific Consultants International, Almec Corporation, March 2004

Kreindler, Gabriel (2016), Driving Delhi? Behavioural Responses to Driving Restrictions, working paper.

Kwon, Jaimyoung and Pravin Varaiya (2008), Effectiveness of California's High Occupancy Vehicle (HOV) system, Transportation Research Part C 16 (2008) 98-115.

Mochtar, Muhammad Zulkifli and Yasuo Hino (2006), Principal Issues to Improve the Urban Transport Problems in Jakarta, Mem. Fac. Eng., Osaka City Univ., Vol. 47, pp. 31-38.

Pereira, Rafael. H. M. and Schwanen, Tim (2013). Commute time in Brazil, 1992-2009: differences between metropolitan areas, by income levels and gender, ipea discussion paper number 1813a, http://www.ipea.gov.br/portal/images/stories/PDFs/TDs/td_1813a.pdf

Steinberg, Richard and Zangwill, Willard I. (1983), The Prevalence of Braess' Paradox, Transportation Science. Vol. 17 Issue 3, p301.

Susilo, Yusak O., Joewono, Tri Basuki, Santosa, Wimpy and Danang Parikesit (2007), A Reflection of Motorization and Public Transport in Jakarta Metropolitan Area, IATSS Research Vol.31 No.1, pp. 59-68.

Transport for London (TfL) (2006), Central London Congestion charging, Impacts monitoring, Fourth Annual Report, June 2006. 


\section{Figure 1: Jakarta Traffic Network Map}
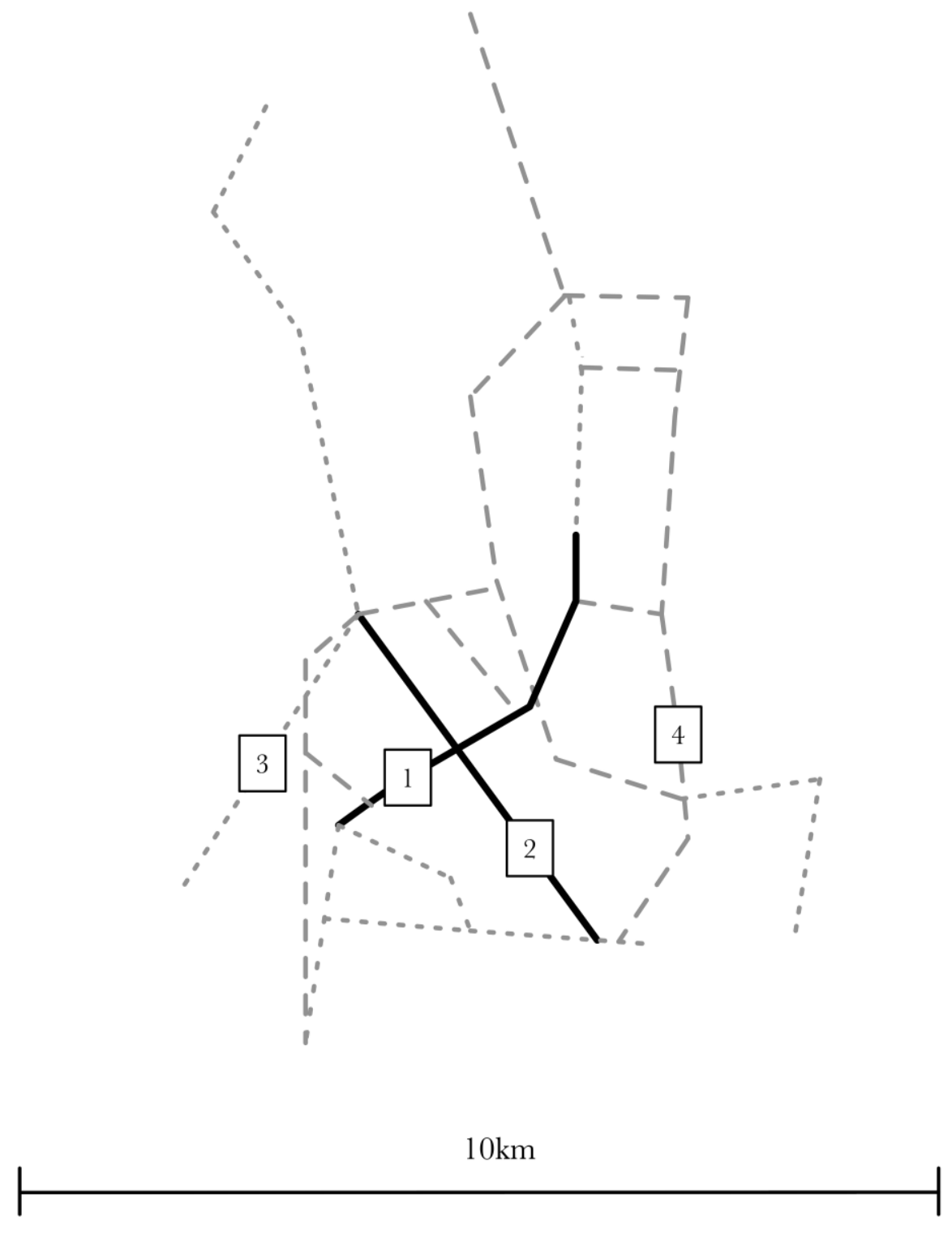

\begin{tabular}{|c|c|c|c|}
\hline Former 3-in-1 & & Jl. Sudirman & 1 \\
\hline & & Jl. Gatot Subroto & 2 \\
\hline & & Jl. Tentara Pelajar & 3 \\
\hline Alternate (Other) & $\ldots$. & Jl. Rasuna Said & 4 \\
\hline
\end{tabular}

Notes: This figure was created in two steps. First, GPS Visualizer was used to draw a map of the pairs of latitude and longitude cordinates for which we collected data from the Google Maps Distance Matrix API. Second, OmniGraffle was used to stylize the map. 

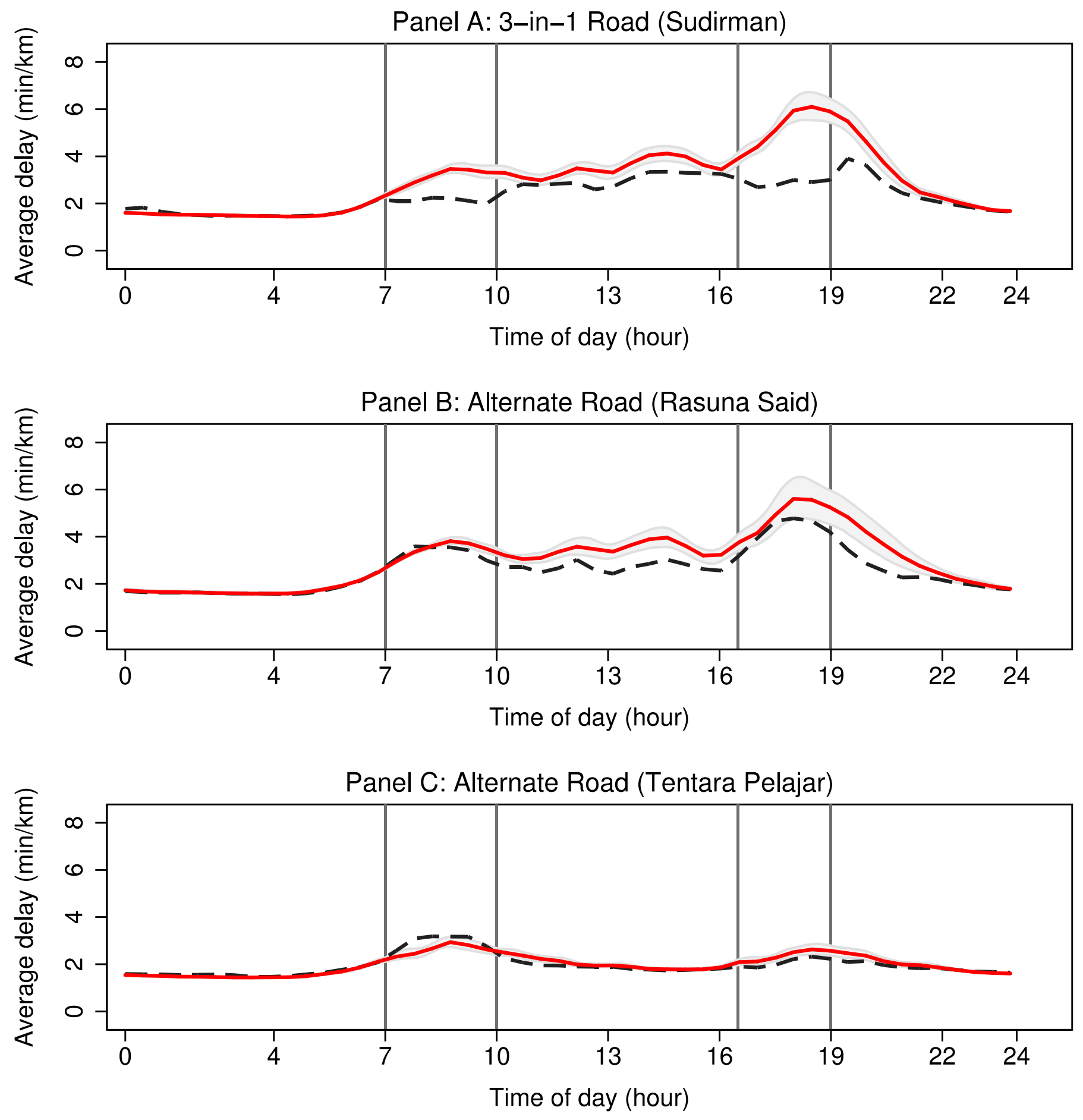

- - - Live before policy lifting __ Live after policy lifting

Notes: Live data are described in Section II.B. Pre-policy change data are from the evening of Thursday, March 31, and all day Friday, April 1 and Monday, April 4. Post-policy change data are from all weekdays: April 5 - May 4.Confidence intervals are calculated using a bootstrapping procedure that adjusts for clusters at the level of date and road direction. For departure times between 6:00 a.m. and 4:30 p.m., when only pre-data from April 1 and April 4 are available, there are 48 clusters. For departure times between 4:30 p.m. and 6:00 a.m., when March 31 pre-data are also included, there are 50 clusters. 
Figure 3: Travel Delay Predicted vs. Post-Policy Lifting on 3-in-1 and Alternate Roads
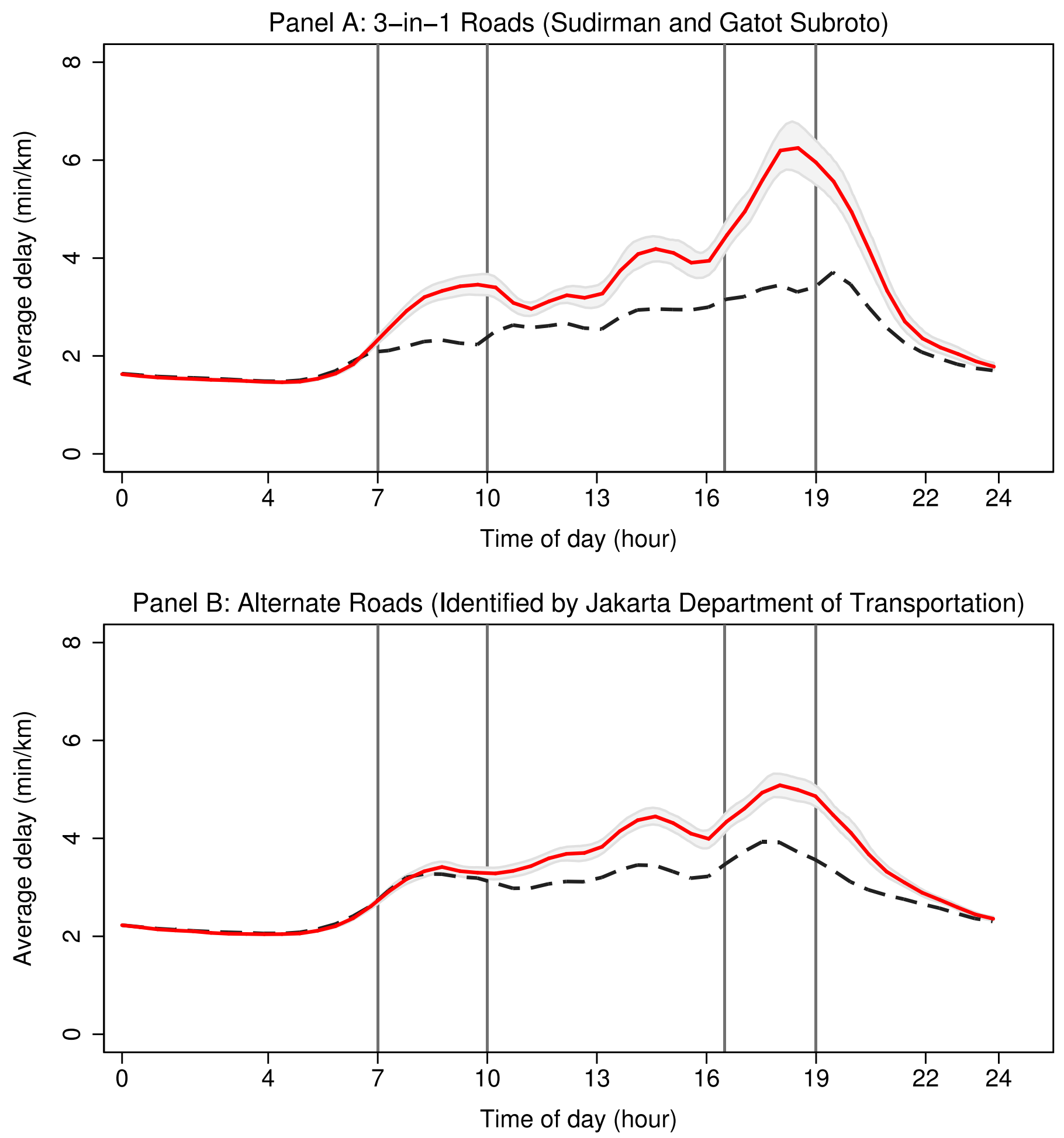

- - - Predicted L Live after policy lifting

Notes: Live and predicted data are described in Section II.B. Post-policy lifting data are from all weekdays, April 28 - June 3. Confidence intervals are calculated using a bootstrapping procedure that adjusts for 54 clusters at the level of date and road direction. 
Figure 4A: Travel Delay on 3-in-1 Roads (Sudirman and Gatot Subroto)
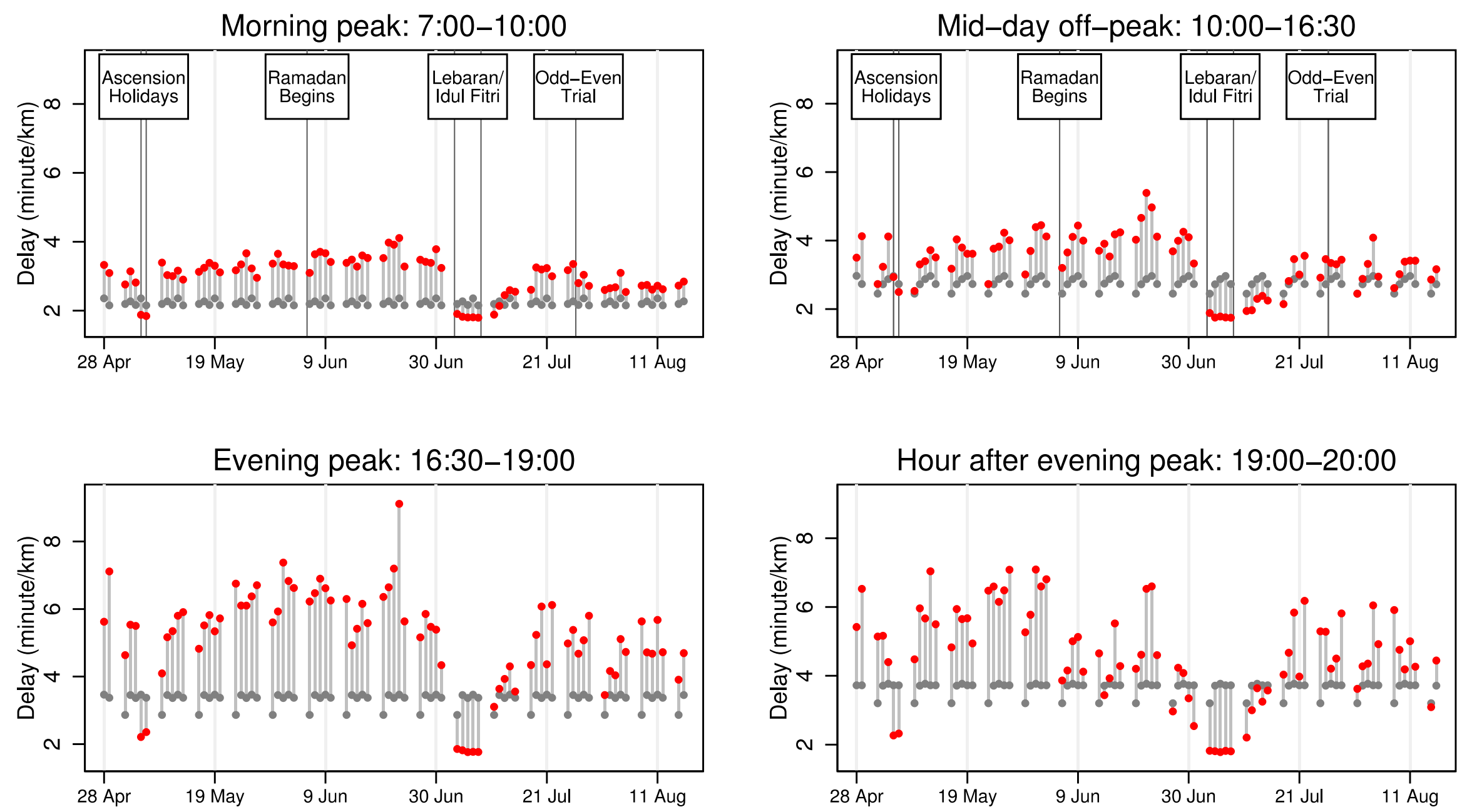

\section{- Live after policy lifting - Predicted}

Notes: Live and predicted data are described in Section II.B. Post-policy lifting data are from

all weekdays, April 28 - August 16. Predicted data varies at the day of the week level, and thus is repeated

for each week in the sample. Each point represents the average delay for departure times in the interval

specified by the panel title. 
Figure 4B: Travel Delay on Alternate Roads

Morning peak: 7:00-10:00

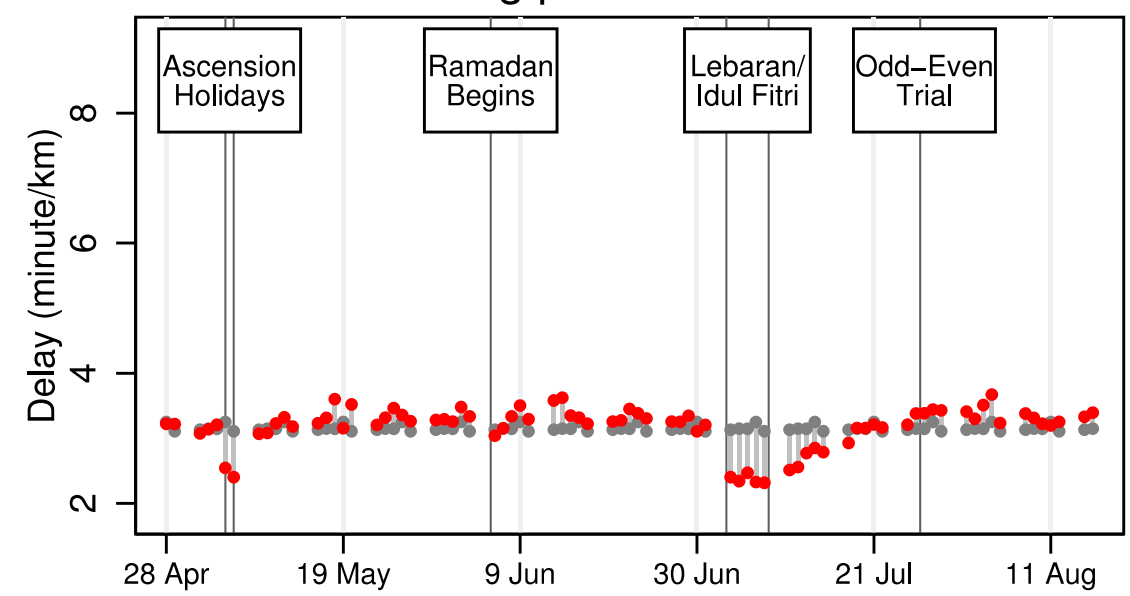

Evening peak: 16:30-19:00

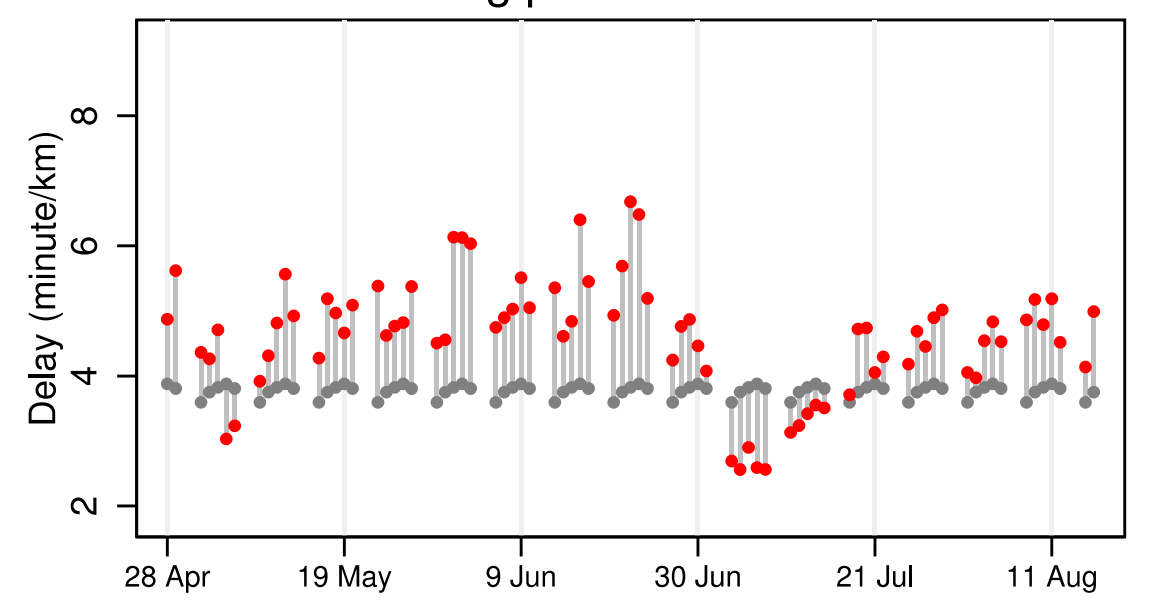

Mid-day off-peak: 10:00-16:30

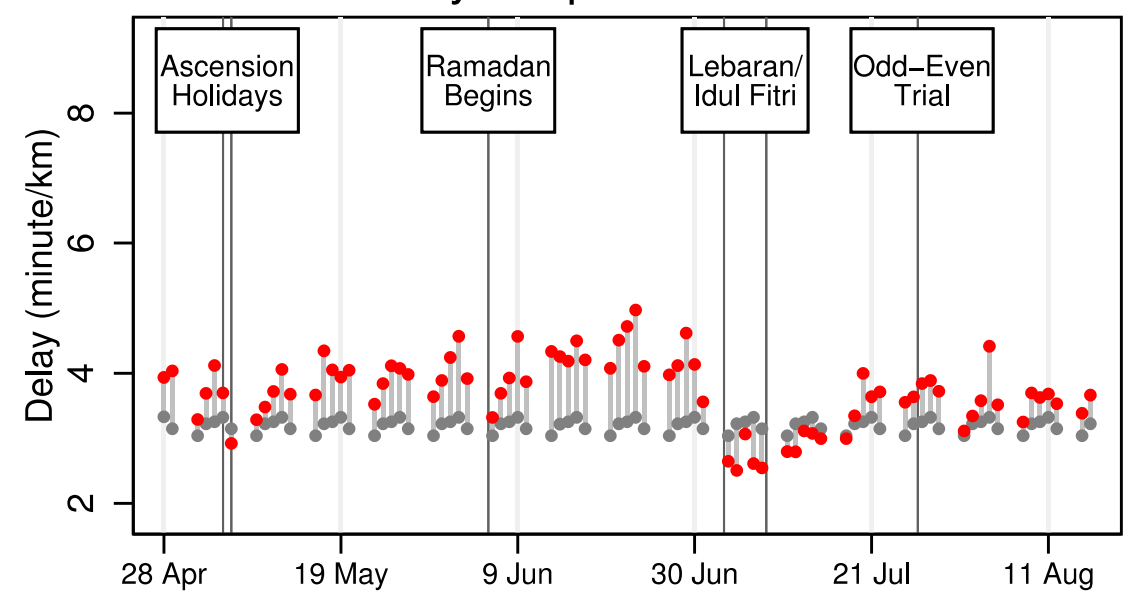

Hour after evening peak: 19:00-20:00

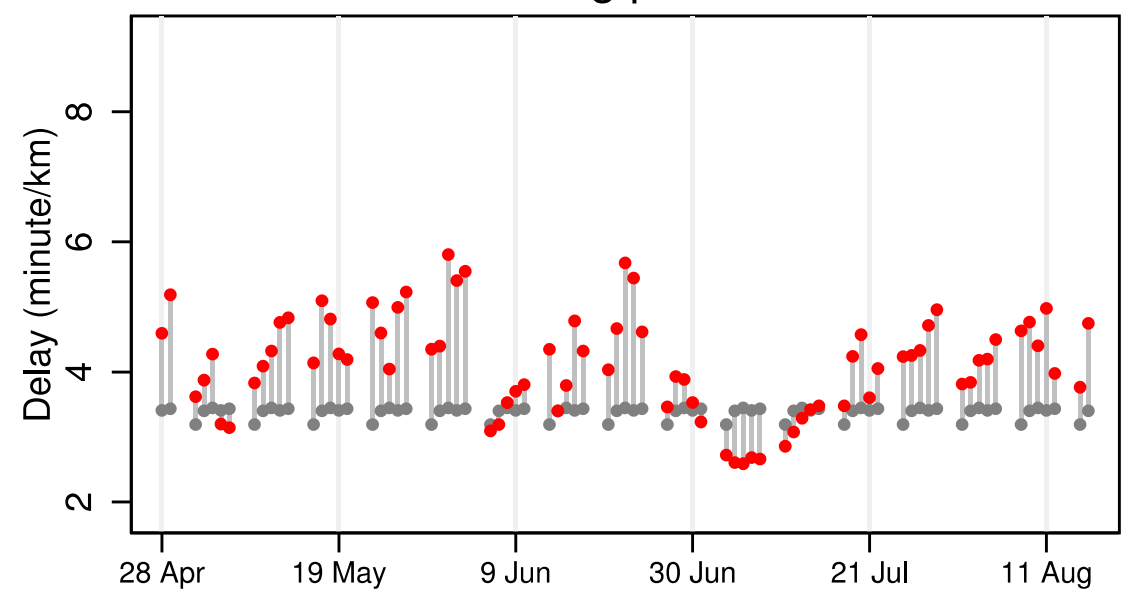

- Live after policy lifting - Predicted

Notes: This figure replicates Figure 4A for 10 alternate routes identified by the Jakarta Department of Transportation. See Figure 4A notes. 
Table 1. Travel Delay Pre- vs. Post-Policy Lifting on 3-in-1 and Alternate Roads

Panel A: Delay on 3-in-1 Road (Sudirman)

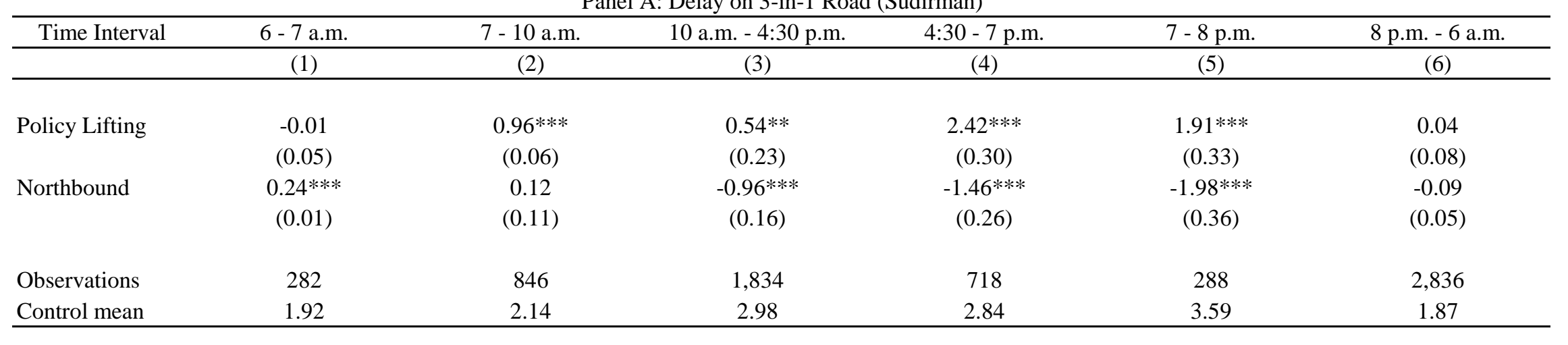

Panel B: Delay on Alternate Road (Rasuna Said)

\begin{tabular}{|c|c|c|c|c|c|c|}
\hline \multirow[t]{2}{*}{ Policy Lifting } & 0.03 & 0.11 & $0.72 * * *$ & $0.57 * * *$ & $1.25 * * *$ & $0.15^{*}$ \\
\hline & $(0.03)$ & $(0.09)$ & $(0.13)$ & $(0.19)$ & $(0.36)$ & $(0.09)$ \\
\hline Northbound & $-0.07 * * *$ & -0.14 & $-0.79 * * *$ & $-4.21 * * *$ & $-3.97 * * *$ & $-0.76 * * *$ \\
\hline Observations & 282 & 846 & 1,834 & 718 & 288 & 2,836 \\
\hline Control mean & 2.19 & 3.34 & 2.71 & 4.35 & 3.61 & 1.89 \\
\hline
\end{tabular}

Panel C: Delay on Alternate Road (Tentara Pelajar)

\begin{tabular}{|c|c|c|c|c|c|c|}
\hline Policy Lifting & $\begin{array}{l}-0.01 \\
(0.03)\end{array}$ & $\begin{array}{l}-0.36 \\
(0.38)\end{array}$ & $\begin{array}{c}0.12 \\
(0.07)\end{array}$ & $\begin{array}{c}0.28 * * \\
(0.10)\end{array}$ & $\begin{array}{l}0.36^{*} \\
(0.18)\end{array}$ & $\begin{array}{l}-0.04 \\
(0.03)\end{array}$ \\
\hline Northbound & $\begin{array}{c}0.22 * * * \\
(0.05)\end{array}$ & $\begin{array}{l}0.29 * \\
(0.15)\end{array}$ & $\begin{array}{l}-0.04 \\
(0.05)\end{array}$ & $\begin{array}{l}-0.16 \\
(0.12)\end{array}$ & $\begin{array}{c}-0.53 * * * \\
(0.17)\end{array}$ & $\begin{array}{l}-0.04 * \\
(0.02)\end{array}$ \\
\hline Observations & 282 & 846 & 1,834 & 718 & 288 & 2,836 \\
\hline Control mean & 1.92 & 2.98 & 1.89 & 2.09 & 2.13 & 1.68 \\
\hline
\end{tabular}

Notes: Columns 1-6 explore how traffic delay, measured in minutes per kilometer, changed following the lifting of the 3-in-1 policy. The sample is panel data for routes and departure times. Departure times cover 20 minute intervals on weekdays between Thursday, March 31 and Wednesday, May 4, with two observations per route, corresponding to the two road directions. The sample in each column is restricted to the departure time interval (open on the right) indicated in the column header. Only evening data are available for March 31, our first date of data collection. In Columns 1-4, where only pre-data from April 1 and April 4 are used, standard errors reported in paratheses are adjusted for 48 clusters at the level of date and road direction . In Columns 5 and 6 , where March 31 pre-data are also included, standard errors are adjusted for 50 clusters at the level of date and road direction.

$* \mathrm{p}<.10, * * \mathrm{p}<.05, * * * \mathrm{p}<.01$ 
Table 2. Travel Delay Predicted vs Post- Policy Lifting on 3-in-1 and Alternate Roads

Panel A: Delay on All 3-in-1 Roads (Sudirman and Gatot Subroto)

\begin{tabular}{|c|c|c|c|c|c|c|}
\hline Time Interval & $6-7$ a.m. & 7 - 10 a.m. & 10 a.m. $-4: 30$ p.m. & 4:30 - 7 p.m. & $7-8$ p.m. & 8 p.m. -6 a.m. \\
\hline & (1) & $(2)$ & $(3)$ & $(4)$ & $(5)$ & $(6)$ \\
\hline Policy Lifting & $\begin{array}{l}-0.02 \\
(0.02)\end{array}$ & $\begin{array}{c}0.88 * * * \\
(0.08)\end{array}$ & $\begin{array}{c}0.82 * * * \\
(0.11)\end{array}$ & $\begin{array}{c}2.29 * * * \\
(0.19)\end{array}$ & $\begin{array}{c}1.98 * * * \\
(0.21)\end{array}$ & $\begin{array}{c}0.19 * * * \\
(0.04)\end{array}$ \\
\hline Northbound & $\begin{array}{c}0.18 * * * \\
(0.03)\end{array}$ & $\begin{array}{l}-0.09 \\
(0.11)\end{array}$ & $\begin{array}{l}-0.19 \\
(0.15)\end{array}$ & $\begin{array}{c}-0.75 * * \\
(0.29)\end{array}$ & $\begin{array}{c}-1.08 * * * \\
(0.35)\end{array}$ & $\begin{array}{c}-0.18 * * * \\
(0.05)\end{array}$ \\
\hline Observations & 384 & 1,152 & 2,504 & 960 & 384 & 3,845 \\
\hline Control mean & 1.93 & 2.23 & 2.75 & 3.31 & 3.63 & 1.83 \\
\hline
\end{tabular}

Panel B: Delay on Alternate Roads (Identified by Jakarta Department of Transportation)

\begin{tabular}{|c|c|c|c|c|c|c|}
\hline \multirow[t]{2}{*}{ Policy Lifting } & $-0.02 * *$ & 0.06 & $0.67 * * *$ & $1.07 * * *$ & $1.15 * * *$ & $0.13 * * *$ \\
\hline & $(0.01)$ & $(0.05)$ & $(0.09)$ & $(0.12)$ & $(0.10)$ & $(0.02)$ \\
\hline \multirow[t]{2}{*}{ Northbound } & $0.22 * * *$ & $0.49 * * *$ & $0.46^{* * *}$ & $0.40 * *$ & 0.02 & $0.06 * *$ \\
\hline & $(0.01)$ & $(0.06)$ & $(0.10)$ & $(0.19)$ & $(0.17)$ & $(0.03)$ \\
\hline Observations & 384 & 1,152 & 2,512 & 960 & 389 & 3,852 \\
\hline Control mean & 2.44 & 3.16 & 3.2 & 3.77 & 3.38 & 2.33 \\
\hline
\end{tabular}

Notes: This table replicates Table 1 for a sample including all former 3-in-1 roads and ten alternate routes to 3-in-1 roads for weekdays between Thursday, April 28 and Friday, June 3. Since data were not gathered for all alternate routes before the 3-in-1 policy was lifted, predicted data is used to provide a control. Standard errors reported in paratheses are adjusted for 54 clusters at the level of date and road direction. See Table 1 Notes.

$* \mathrm{p}<.10, * * \mathrm{p}<.05, * * * \mathrm{p}<.01$ 